\title{
Effect of probiotics on total salivary antioxidant level and physical properties of saliva:An ex-vivo study
}

\begin{abstract}
Background: Role of oxidative stress in pathophysiology of various diseases has already been established. Antioxidants act as free radical scavenger and prevent damage to cell, at the same time affects the metabolism of several pathogenic microbes. With increasing incidence of antibiotic resistance, alternative therapeutic treatment options are coming into picture. WHO claims probiotics to be the next most important immune defence system following antibiotic resistance. Even though there are several studies emphasising on the positive outcome of probiotics on diseases, their exact mechanism of action still remains debatable. The present study tried to unveil the antioxidant property of probiotics in saliva along with its effect on salivary $\mathrm{pH}$ and buffering capacity.
\end{abstract}

Methods: Unstimulated saliva from 10 individuals were analysed for total antioxidant level, $\mathrm{pH}$ and buffering capacity using spectrophotometer, $\mathrm{pH}$ paper and buffering strips respectively, before and after probiotic intake for 2 weeks.

Results: Probiotic intake led to increase in total salivary antioxidant level with no significant changes in $\mathrm{pH}$ and buffering capacity. Results obtained were statistically analysed using "paired t-test".

Conclusions: Probiotics are effective in increasing antioxidant level thereby minimizing cellular damage and hence can be used for prevention of several diseases. Also increase in antioxidant level can be easily assessed in saliva, thus, saliva can be used as a routine diagnostic tool.

Keywords: probiotics, saliva as biomarker, salivary antioxidant level, salivary $\mathrm{pH}$, buffering capacity of saliva
Volume I 3 Issue 2 - 202 I

\author{
Mithra N Hegde,' Mrinalini \\ 'Head of the Department, Department of Conservative \\ Dentistry and Endodontics, AB Shetty Memorial institute of \\ Dental Sciences, Nitte deemed to be university, India \\ ${ }^{2}$ Post Graduate Student, Department of Conservative Dentistry \\ and Endodontics, $A B$ Shetty Memorial institute of Dental \\ Sciences, Nitte deemed to be university, India
}

\begin{abstract}
Correspondence: Prof. Dr. Mithra N Hegde, Head of the Department, Department of Conservative Dentistry and Endodontics, AB Shetty Memorial institute of Dental Sciences, Nitte deemed to be university, Mangaluru, Karnataka, India, Tel 98452844I I, Email drhegdedentist@gmail.com
\end{abstract}

Received: February 27, 2019 | Published: March 09, 2021

\section{Background}

Oxidative stress is a homeostatic event that arises due to imbalance in pro-oxidant and antioxidant level in the cell. ${ }^{1}$ Such disparity results in generation of free radicals leading to lipid peroxidation, protein denaturation, DNA hydroxylation and ultimately causes apoptosis of the cell. ${ }^{2}$ Excessive amount of these reactive radicals compromises the cell viability and contributes to several diseases including the ones associated with oral cavity like dental caries, periodontitis and oral precancerous lesions. ${ }^{3}$ With wide emergence of disease over the past few years and the knowledge of oxidative stress being a major determinant in their pathophysiology has shifted our preventive and therapeutic focus towards antioxidant modality. ${ }^{4}$ One such innovative approach is bacteriotherapy using probiotics. Probiotics refer to live non-pathogenic microorganisms which when administered in adequate amounts, confer health benefits. ${ }^{5}$ This good old concept of bacteriotherapy has been known for its beneficial effect and are said to be helpful in reducing oxidative stress, thereby minimizing the damage. ${ }^{6}$ However, exact mechanism is yet to be deciphered. Evidence has showed that probiotic bacteria exhibit significant antioxidant abilities both in in-vitro as well as in-vivo. ${ }^{7-10}$ However, the clinical studies performed, evaluated the antioxidant property of probiotics in plasma.

Saliva being an alternative diagnostic tool poses several advantages over plasma. Its availability, easy collection, possibility of repeated non-invasive sampling, simpler technique and faster interpretation makes it ideal for screening, diagnosing and monitoring various diseases. ${ }^{11}$ Very few studies have been performed on understanding the pathophysiology of oxidative stress in saliva and the potential role of probiotics on salivary antioxidant level have never been evaluated. Also the effect of probiotics on salivary buffering capacity and $\mathrm{pH}$ is not well understood. Thus, the aim of the study was to evaluate the effect of probiotics on total salivary antioxidant level and physical properties of saliva ( $\mathrm{pH}$ and buffering capacity).

\section{Material and methods}

\section{Armamentarium used:}
a) Sterile saliva container
b) Probiotic drink (Yakult)
c) Glass tube and pipettes
d) Buffering and $\mathrm{pH}$ strips (GC Saliva Check Kit)
e) Centrifugation machine
f) Hot water bath
g) Spectrophotometer

\section{Subject recruitment}

After obtaining the institutional ethical clearance (ABSM/ EC06/2019), study was conducted in the month of January over a period of 2 weeks. Only subjects who had given voluntary informed consent were included in the study. 
Inclusion and Exclusion criteria were developed.

\section{Inclusion criteria:}

a. Healthy individuals in the age group of 20-35 years

\section{Exclusion criteria:}

a. Individuals with habit of alcohol consumption and smoking.

b. Individuals with any systemic condition

\section{Saliva collection}

On the day of saliva collection, subjects were instructed not to eat or drink anything for at least 1 hour prior to the collection. To control circadian variations, samples were collected between 9-10 a.m.

\section{Methodology}

Saliva was allowed to accumulate in the floor of the mouth and subjects were instructed to collect it into sterile saliva vial (Passive drool method). Samples were transported to the laboratory within 30 minutes of collection. Salivary analysis was done for $\mathrm{pH}$, buffering capacity and total antioxidant level within 1 hour.

a. Subjects were then provided with probiotic drink (Yakult) with one drink per day for a period of 2 weeks.

b. The entire procedure for salivary total antioxidant level, $\mathrm{pH}$ and buffering capacity was repeated after 14 days of probiotic intake and comparison was made between the 3 parameters (Table 1).

Table I Buffering capacity, $\mathrm{pH}$, Total salivary antioxidant level before and after probiotic administration

\begin{tabular}{lllllll}
\hline \multirow{2}{*}{ Sample No. } & \multicolumn{2}{l}{ Buffering capacity } & pH & \multicolumn{2}{l}{ Total antioxidant capacity In Mm/L } \\
\cline { 2 - 7 } & Before & After & Before & After & Before & After \\
\hline 1 & 4 & 4 & 7 & 7.2 & 1.283 & 1.257 \\
2 & 4 & 3 & 6.8 & 6.8 & 0.988 & 1.492 \\
3 & 4 & 4 & 7.4 & 7.2 & 0.746 & 1.224 \\
4 & 3 & 3 & 7.6 & 7.6 & 0.814 & 1.002 \\
5 & 4 & 3 & 7.4 & 7.2 & 0.71 & 1.377 \\
6 & 4 & 4 & 7 & 6.8 & 0.809 & 0.783 \\
7 & 4 & 4 & 7.2 & 7.4 & 0.983 & 1.225 \\
8 & 4 & 4 & 6.8 & 6.8 & 1.097 & 1.269 \\
9 & 3 & 3 & 7.2 & 7.2 & 1.124 & 1.435 \\
10 & 4 & 4 & 7.2 & 7.4 & 0.869 & 1.328 \\
\hline
\end{tabular}

\section{Estimation of total antioxidant level}

100 microliter of saliva was pipetted into the test tube to which $5 \%$ trichloroacetic acid was added. It was then allowed to settle for 5 minutes followed by centrifugation for 10 minutes. $1 \mathrm{~mL}$ of total antioxidant reagent was added to 100 microliter of the supernatant saliva. This mixture was incubated in hot water bath at $90^{\circ} \mathrm{C}$ for 90 min. Optical density was read at $695 \mathrm{~nm}$ using spectrophotometer.

\section{Estimation of buffering capacity and $\mathrm{pH}$}

Adequate amount of saliva was placed on buffering strips and colour change was noted. $\mathrm{pH}$ paper was dipped in the remaining saliva present in vial and change in colour was observed. Interpretation was made based on the colour guide present in the GC Salivary Check kit.

\section{Statistical analysis}

Data obtained were statistically analysed by using IBM SPSS version 24. Differences between variables were analysed by "paired t- test". Descriptive analysis was performed by noting means and standard deviations (Table 2). Variables were plotted on a statistical graph to compare $\mathrm{pH}$, buffering capacity and total antioxidant level before and after probiotic administration.

Table 2 Statistical analysis

\begin{tabular}{|c|c|c|c|c|c|c|c|c|c|}
\hline \multirow[t]{2}{*}{ Different parameters } & & \multirow[t]{2}{*}{$\mathbf{N}$} & \multirow[t]{2}{*}{ Mean (SD) } & \multirow{2}{*}{$\begin{array}{l}\text { Mean } \\
\text { difference }\end{array}$} & \multicolumn{2}{|c|}{$\begin{array}{l}95 \% \text { Confidence interval } \\
\text { of the difference }\end{array}$} & \multirow[t]{2}{*}{$\mathbf{t}$} & \multirow{2}{*}{ df } & \multirow{2}{*}{ p-value } \\
\hline & & & & & Lower & Upper & & & \\
\hline \multirow[b]{2}{*}{ Buffering capacity } & Before & 10 & $3.80(0.42)$ & \multirow[b]{2}{*}{0.3} & \multirow[b]{2}{*}{-0.05} & \multirow[b]{2}{*}{0.65} & \multirow[b]{2}{*}{1.96} & \multirow[b]{2}{*}{9} & \multirow[b]{2}{*}{$0.08(\mathrm{NS})$} \\
\hline & After & 10 & $3.50(0.53)$ & & & & & & \\
\hline \multirow{2}{*}{$\mathrm{pH}$} & Before & 10 & $7.16(0.26)$ & \multirow{2}{*}{0} & \multirow{2}{*}{-0.12} & \multirow{2}{*}{0.12} & \multirow{2}{*}{0} & \multirow{2}{*}{9} & \multirow{2}{*}{$\mathrm{I} .00$ (NS) } \\
\hline & After & 10 & $7.16(0.28)$ & & & & & & \\
\hline \multirow[b]{2}{*}{ Total antioxidant level } & Before & 10 & $0.94(0.19)$ & \multirow[b]{2}{*}{-0.3} & \multirow[b]{2}{*}{-0.46} & \multirow[b]{2}{*}{-0.13} & \multirow[b]{2}{*}{-4.08} & \multirow[b]{2}{*}{9} & \multirow[b]{2}{*}{$0.003 *$} \\
\hline & After & 10 & $1.24(0.21)$ & & & & & & \\
\hline
\end{tabular}

Paired $t$ test

$*_{p}<0.05$ Statistically Significant, p $>0.05$ Non Significant, NS

Citation: Hegde MN, Mrinalini. Effect of probiotics on total salivary antioxidant level and physical properties of saliva:An ex-vivo study.J Otolaryngol ENT Res. 202 I; I3(2): I3-I6. DOI: I0.15406/joentr.202I.I3.00483 


\section{Discussion}

Lactobacillus and Bifidobacterium are two of the most widely used bacteria as probiotics. Use of lactic acid bacteria for therapeutic action in oral cavity was controversial but recent studies have shown its promising result in dental caries, periodontitis, halitosis and several other oral pathologies. ${ }^{12}$ In the present study administration of probiotics led to no significant change in $\mathrm{pH}$ of saliva (Figure 1). This finding corroborate with the findings of Quingru Jiang et al who has also observed no significant change in $\mathrm{pH}$ after incorporating probiotic bacteria in biofilm. ${ }^{13}$ The unaltered $\mathrm{pH}$ phenomenon in the present study might be explained by 2 means:

$\mathrm{pH}$
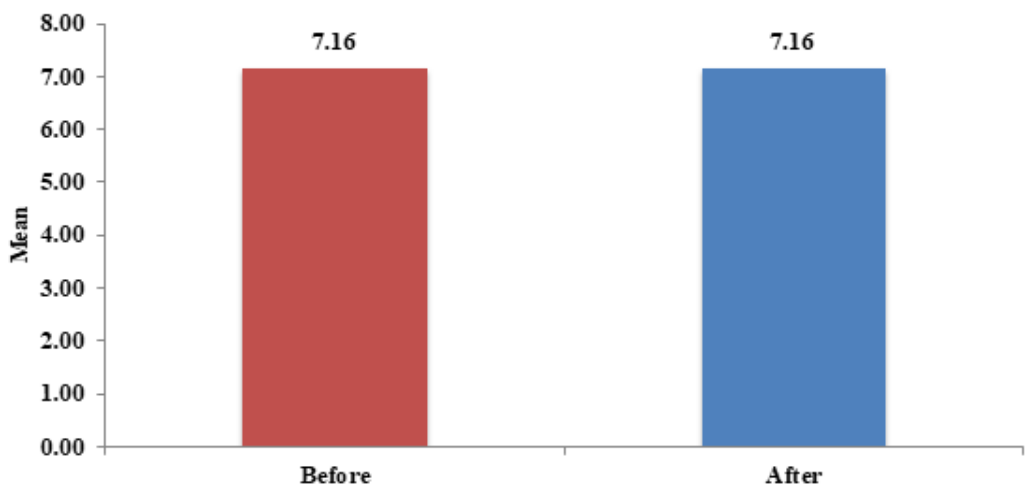

Study Phase

Figure I Change in $\mathrm{pH}$ before and after probiotic intake.

p-value: 1.00 (Non-significant).

a) The acids produced by Lactobacillus were utilised by the other micro-organisms in the oral cavity and thus, did not affect the environment.

b) Lactobacillus cells comprised only a small part in the saliva, so the acids generated by them did not alter the $\mathrm{pH}$.

Saliva buffer acts as an important host defence mechanism to control the $\mathrm{pH}$ of the mouth environment. ${ }^{14}$

There was no significant change in buffering capacity of saliva after probiotic intake for 2 weeks (Figure 2). This result was in contrast to a study done by Villavicencio in the year 2018 who observed increase in buffering capacity following probiotic administration. ${ }^{15}$

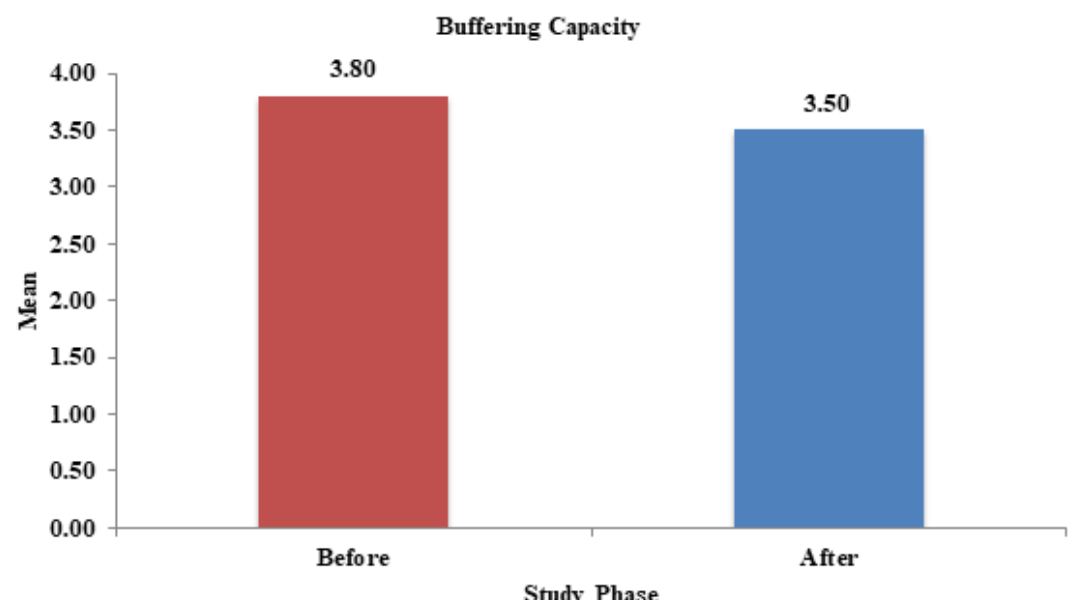

Figure 2 Change in buffering capacity before and after probiotic intake.

p-value: 0.08 (Non-significant).

This result can be due to:

a) As no significant change in $\mathrm{pH}$ was noted which implies there is no significant ionic interactions due to administration of probiotics resulting in unaltered buffering capacity.

b) Also the study was conducted over a short period of time unlike other studies which were carried out for a minimum of 6 months.

Lastly, the total antioxidant level in saliva increased after administration of probiotics (Figure 3 ). This finding corroborates with

the findings of a study done by Martareli et al which concluded that probiotics leads to increase in plasma antioxidant level. ${ }^{10}$

This result can be attributed to:

a) The probiotic drink used in the study consisted of Lactobacillus which is said to have superoxide dismutase activity.

b) Also exchange between plasma and saliva takes place via active as well as passive diffusion leading to presence of biomarkers in saliva. 


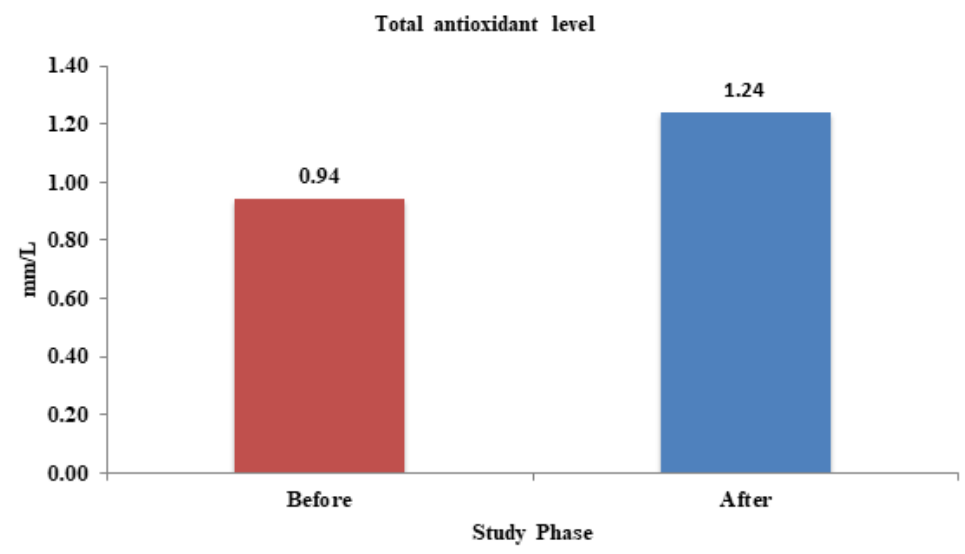

Figure 3 Effect of probiotics on total antioxidant level before and after probiotic administration.

p-value: 0.003 (Significant).

\section{Conclusion}

Till date probiotics were known to balance the microbial ecology. But it acts at cellular level as well. Probiotics increase antioxidant level in the body. These antioxidants prevent free radical generation and thus, interrupt damage to human cell. At the same time it also affects the metabolism of several microbial cells including the ones responsible for oral diseases. Moreover, change in antioxidant level following probiotics can be easily appreciated in saliva. Thus, saliva can be practiced as a routine diagnostic tool for assessing total antioxidant level. It can further be used to evaluate the effect of probiotics on specific antioxidant system related to particular disease.

\section{Acknowledgments}

None.

\section{Conflicts of interest}

None.

\section{Funding}

None.

\section{References}

1. Rahal A, Kumar A, Singh V, et al. Oxidative stress, prooxidants, and antioxidants: the interplay. Biomed Res Int. 2014;2014:761264.

2. Kamodyová N, Červenka T, Celec P. Salivary markers of oxidative stress in oral diseases. Front Cell Infect Microbiol. 2015;20;5:73.

3. Liguori I, Russo G, Curcio F, et al. Oxidative stress, aging, and diseases. Clin Interv Aging. 2018;13:757-772.

4. Firuzi O, Miri R, Tavakkoli M, et al. Antioxidant therapy: current status and future prospects. Curr Med Chem. 2011;18(25):3871-388.
5. Williams NT. Probiotics. Am J Health Syst Pharm. 2010;67(6):449-458.

6. Mohammadi AA, Jazayeri S, Khosravi-Darani K, et al. Effects of probiotics on biomarkers of oxidative stress and inflammatory factors in petrochemical workers: a randomized, double-blind, placebo-controlled trial. Int J Prev Med. 2015;6(1):82.

7. Shen Q, Shang N, Li P. In vitro and in vivo antioxidant activity of Bifidobacterium animalis 01 isolated from centenarians. Curr Microbiol. 2011;62(4):1097-1103.

8. Wang Y, Wu Y, Wang Y, et al. Bacillus amyloliquefaciens SC06 alleviates the oxidative stress of IPEC-1 via modulating Nrf2/Keap1 signaling pathway and decreasing ROS production. Appl Microbiol Biotechnol. 2016;101(7):1-12.

9. Persichetti E, De Michele A, Codini M, et al. Antioxidative capacity of Lactobacillus fermentum LF31 evaluated in vitro by oxygen radical absorbance capacity assay. Nutrition. 2014;30(7-8):936-938.

10. Martarelli D, Verdenelli MC, Scuri S, et al. Effect of a probiotic intake on oxidant and antioxidant parameters in plasma of athletes during intense exercise training. Curr Microbiol. 2011;62(6):1689-1696.

11. Javaid MA, Ahmed AS, Durand R, et al. Saliva as a diagnostic tool for oral and systemic diseases. J Oral Biol Craniofac Res. 2016;6(1):67-76.

12. Haukioja A. Probiotics and oral health. Eur J Dent. 2010;4(3):348-355.

13. Jiang Q, Kainulainen V, Stamatova I, et al Lactobacillus rhamnosus GG in Experimental Oral Biofilms Exposed to Different Carbohydrate Sources. Caries Res. 2018;52(3):220-229.

14. Malekipour MR, Messripour M, Shirani F. Buffering capacity of saliva in patients with active dental caries. Asian J Biochem. 2008;3(5):280-283.

15. Villavicencio J, Villegas LM, Arango MC, et al. Effects of a food enriched with probiotics on Streptococcus mutans and Lactobacillus spp. salivary counts in preschool children: a cluster randomized trial. J Appl Oral Sci. 2018;26: e20170318. 